\title{
DEVELOPMENT AND EVALUATION OF A FRAMEWORK FOR CREATING WEB-BASED LEARNING MODULES: A PEDAGOGICAL AND SYSTEMS PERSPECTIVE
}

\author{
Thomas Janicki \\ University of North Carolina - Wilmington \\ Cameron School of Business \\ Wilmington, NC 26403 \\ janickit@uncwil.edu \\ 910.962.4077 \\ 910.962 .3815 (fax) \\ Jens O. Liegle \\ Georgia State University \\ Computer Information Systems Department \\ Atlanta, GA 30302 \\ jliegle@gsu.edu \\ 404.463.9140 \\ $404.651 .3842(\mathrm{fax})$ ]
}

\begin{abstract}
Educational content on the Internet is rapidly increasing. Educational institutions and businesses are placing more course material online to supplement classroom and business training situations. Prior researchers have reported that this new web-based training technology (which has its foundation in computer-based training) has not integrated sound pedagogical practices into the authoring process when developing new tutorials. This research merges theories from the instructional design and web-based design researchers in a framework for more effective webbased tutorials. To test the effectiveness of this model, a prototype computer system is developed. This system named WeBTAS (Web-Based Tutoring Authoring System) is reviewed by two different panels of educators. These panels report that the prototype system does promote five different learning principles as part of the authoring process. In addition the system was implemented on a pilot test basis and its initial observations are that it produces an average of $15 \%$ more learning content in the same development time as conventional authoring tools.
\end{abstract}

\section{KEYWORDS}

Asynchronous Learning Networks, Computer-Based Training Instructional Technology, Just-InTime Training, Web-Based Training 


\section{INTRODUCTION}

Educational content on the Internet is rapidly increasing. Educational institutions are placing more course material on-line to supplement and sometimes replace classroom instructions. In addition, recognizing potential new marketing opportunities, universities are placing entire courses on the web to attract new students from around the world. Excluding entertainment uses, the typical usage of the web is also changing from a technical orientation to an educational orientation. Professionals from computer technical fields comprised $31.4 \%$ of all web uses in 1995, while individual users for educational purposes totaled $23.7 \%$. In just one year computer occupation users dropped to $29.6 \%$ while educational users jumped to $27.8 \%$ of the web's overall users [Robin \& McNeil, 1997].

Businesses are also utilizing the Internet as the delivery vehicle for a portion of their training needs. Quoted as reasons for Internet delivery of training are the reduction of travel costs, saving of personnel time, the capability to deliver the same consistent program across the nation or world and the flexibility to meet rapidly changing needs (just-in-time training for specific needs) [Liegle \& Madey, 1997]. Businesses pushed the distance training market up by $20 \%$ (in course offerings) between 1994 and 1996 [Barrett-Murie, 1996]. McGee [1998] reports that web-based instructional materials are the fastest growing means to deliver training within business organizations. Supporting this growth in web-based training is a survey completed by business leaders that states educational learning as the fifth most important management issue for the new decade [Niederman et.al, 1991].

Hamalainen et.al. [1996] and Robin \& McNeil [1997] discuss that education has the potential to be the key application in electronic commerce. However, they warn that new technology alone will not make these new web-based tutorials and learning modules more effective. Hamalainen et. al. [1996] predict a gloomy forecast for learning advances in that we can expect only marginal improvements in student performance if web developers continue to re-implement traditional and conventional models borrowed from the classroom. Their prediction is based on a review of the current offerings of web-based educational content that are mostly tutorials that passively transmit information or data. By itself, more technology will not make education more efficient. Robin \& McNeil [1997] also support this opinion and call for new innovation modules of production, presentation and delivery that take advantage of the Internet's power that emphasize the capability of the learners to participate.

This paper investigates current web-based learning modules and then details the development and pilot testing of a prototype computer system that was designed to incorporate pedagogy into the authoring process. It also demonstrates the learning theory components incorporated into the system's design. To clarify the prototype system was designed to assist in the development of small tutorials (approximately ten minutes in duration) that enhance a traditional classroom presentation. The prototype system is not designed to replace a traditional course.

To investigate if the system indeed adds pedagogy to the authoring process this research follows the Dick and Carey [1996] process for the evaluation of instructional technology design systems. Overall, this research analyzes and summarizes the findings from two groups of evaluators. One group of evaluators consisted of a panel of instructional design professionals who were surveyed to determine if the system did incorporate learning principles into the authoring system. The other team of evaluators was comprised of novice collegiate instructors who authored web-based tutorials using the prototype system as their authoring tool.

The paper ends with a summary of the overall findings of the two groups. It details their survey results as well as a list of likes and dislikes expressed by both survey panels. In addition, an analysis of the "outcomes" or tutorials created by the pilot group of developers is presented. It also contrasts the output of the prototype authoring system versus other conventional HTML authoring tools. 


\section{BACKGROUND \& PROBLEM STATEMENTS}

\section{A. Expansion of education content on the Web}

As was noted previously educators are rapidly placing course materials on the web to meet many different needs. An early need was the desire to provide similar course content and learning opportunities to students in rural areas of the country. For example, North Carolina has implemented a telecommunications network called VistaNet that provides advanced levels of course content to smaller secondary and primary schools within the state. This network provides students in smaller rural districts access to the same advanced courses offered at more urban and larger schools. These courses were not being offered at the smaller rural schools due to the cost of providing an instructor for a smaller class enrollment [Patterson and Smith, 1994]. At the collegiate level, schools such as Kent State University and the University of South Carolina beam lectures from one campus to their regional campuses. This provides students at regional campuses the opportunity to enroll in upper level courses without the time and travel costs associated with taking them at the main campus [Atkinson, 1996; Cassidy, 1995].

Just as important are the expanded marketing opportunities that distance education provides to colleges and universities. Traditionally, enrollments at a university were limited by geographic constraints. The pool of potential students was limited to a reasonable commuting distance. However, the web provides the opportunity for students to enroll in the college of their choice regardless of its location. The University of Phoenix with 40,000 students enrolled at over 2,500 locations throughout the world is an example of this new capability [Gubernick \& Eberling, 1997]. The university transmits learning content to corporate office "campuses" as well as directly to individual student homes. New non-traditional suppliers of education such as Mind Extension University (a cable network) and Znet (a publishing company) are providing educational content on the World Wide Web and other communication media to students desiring the anytime-anywhere approach to education.

Higher education institutions are not the only sector placing learning material on the web. Businesses are also turning to the web to help meet its training needs. In just two years businesses have driven the web-based training market up by $20 \%$ [Barrett-Murie, 1996]. The web helps to reduce travel expenses, reduce the time involvement of employees, provides a consistent message to all locations and permits "Just-inTime" training [McGee, 1998; BarrettMurie, 1995].

Some companies don't want to wait for universities to offer the course content that their employees want and need. To overcome this problem, a number of joint ventures between universities and business are emerging. AT\&T has joined with eight universities to provide upper level management courses to specific corporations. These universities provide the content while AT\&T provides the telecommunication services [AT\&T-HREF, 1999], Westcott Inc [HREF, 1999], and Allen Communications [HREF, 1999] provide similar services. Ives and Jarvenpaa [1996] envision additional joint ventures between businesses and educational institutions, as these two types of organizations have complementary goals. Businesses need a pool of talented employees that universities can provide. Conversely, in order for universities to survive in increasingly competitive times, they need to provide an increasingly talented pool of graduates. Businesses can provide experts from their ranks to assist instructors develop real-world problem cases and further act as outside experts to a live classroom experience. Similarly, educational institutions can provide academic research experts to businesses via innovation telecommunication applications.

\section{B. Problems with current web-based offerings}

According to many researchers, the current web-based educational tutorials are generally poor in educational content. The World Wide Web is a relatively new technology and the early adopters 
were individuals skilled in programming and HTML skills, but not necessarily knowledgeable about educational concepts [Murray, 1996]. Murray continues to note that most higher education professors have never had a course in learning theory and as a result their web-based offerings are lacking in real content based on learning theories. Complicating the issue of effective web-based training material is that those professionals who are experts in learning theories (traditional teachers) often lack the technical skills to implement a web-based course.

Bork [1996] also reports that many of the web-based educational offerings provide poor learning opportunities, as they are merely the "translation" of books and lectures into an electronic format. Schank [1998] concurs that the current offerings are not very good, and adds that there is a need for these modules to be based more on learning concepts. His viewpoint is that many of the tutorials on the web were analogous to simply "turning the pages" in a textbook. He notes that the reason that learning modules have not achieved their full educational potential is that information is not learning and that many of these systems present information and data, and do not necessarily teach [Schank, 1993].

Another problem of current web offerings is the cost and time of development. Murray [1996] observed that each offering is generally an independent effort. The developer must start from scratch at significant cost and skills. He calls for a system that provides a template to assist a developer to build a tutorial.

Currently existing are authoring systems that provide a limited set of templates for developers. Examples are WebCT, ToolBook, Director, AuthorWare and TopClass. These tools provide significant file management and some limited HTML assistance so that an average educator can create web-based course content without the need for a deeper knowledge of the underlying technology. However, a major weakness of these systems is that they do not provide assistance to a developer to create learning content based on learning principles or pedagogy [Goldberg et. al., 1996; Lebow, 1996]. On the leading edge, Murray [1998] proposes an authoring system that provides content development based on learning principles. His proposed system combines an intelligent tutoring system with HTML assistance for authors.

Schank [1998], Murray [1998], Hamalainen et. al. [1996], Jonassen et. al. [1995] and Merrill et. al [1996] all call for more research going into the development of new systems that support developers of educational material for the web that is based on pedagogy. A summary of their viewpoints is that this system should be easy for the developer to use, be easy to learn and prompt the author for lesson content based on pedagogy. In addition, this system should be highly interactive and take advantage of the web's capabilities.

In summary, the number of educational offerings on the web will continue to rapidly grow. However the overall effectiveness and quality of the materials published has been questioned. The remainder of this paper reports the development of a web-based tutorial authoring tool based on learning principles and on sound web-based design concept, with the goal to provide instructors a tool that will assist them in the development of more effective learning modules.

\section{DEVELOPMENT OF A MODEL FOR A TUTORIAL AUTHORING SYSTEM}

\section{A. Model Development}

The components and features of the proposed model come from two different streams of researchers. It combines instructional design concepts from the educational and instructional technology fields with those of the information systems and web-based design researchers. 
Figure 1: Summary of Instructional Design Concepts

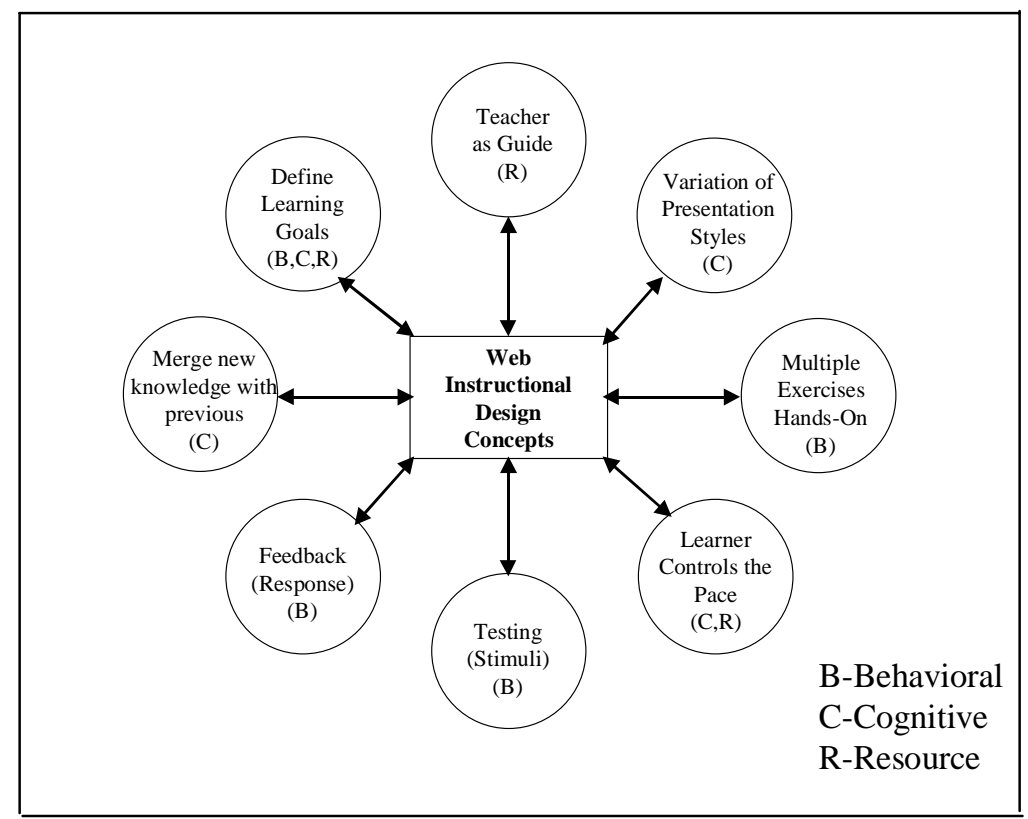

To provide a foundation of pedagogy for learning, a series of instructional design concepts were included in a framework for the model. They were chosen as they repetitively surfaced as the keys to effective learning in research. In addition these components may utilize the web's interactivity in their implementation. Briefly they are a combination of learning theories from the behavioral psychology, cognitive theory and resource based theories of learning. The instructional design concepts shown in Figure 1 consolidates the instructional design activities of Dear [1987], the events of instruction proposed by Gagne, Briggs \& Wager [1988] and Gagne, Wager, \&Rojas [1981] the design guidelines of Hannafin and Peck [1988] and the strategies of instructional design by Merrill [1997].

Table 1: Consolidation of Effective Web-Design Concepts

\begin{tabular}{|lll|}
\hline - Instructor as a facilitator & - Testing \\
- Variety of presentation styles & - Feedback \\
- Multiple exercises & - Clear Navigation \\
- Hands-On problems & - Learner controls the pace & - Consistent Layout \\
\hline
\end{tabular}

Next, effective web-based design concepts were researched. Table 1 summarizes the web-design concepts as offered by Jonassen et. al. [1995], Schank [1998], Murray [1996], Ward \& Lee [1995], Leinder \& Jarvenpaa [1993], Tennyson [1989] Bugbee [1996], Anderson \& Reiser [1985], and Martin [1995]. Similar to the instructional design principles, the concepts shown in Table 1 repetitively surfaced as positive influences on learning and usable.

Figure 2 merges the two schools of research (instructional technology and web-design) to provide a model for more effective web-based tutorials. As can been seen in Figure 2, the prototype authoring system named WeBTAS (Web-Based Tutorial Authoring System) has two major 
functional tasks. The first functional task is shown on the right side of Figure 2 and manages the creation of the HTML programming code, file tracking and the learner logging processes.

Figure 2: WeBTAS (Web-Based Tutoring Authoring System)

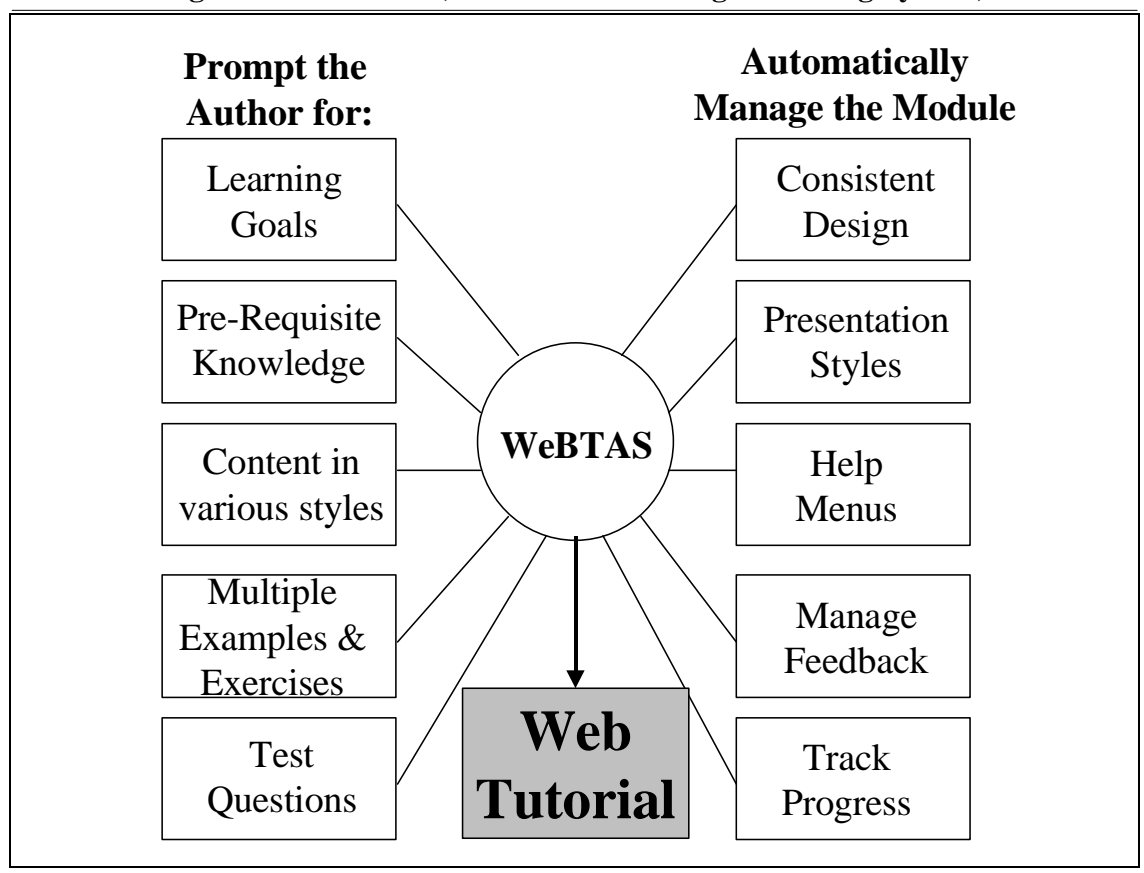

The system facilitates a consistent layout of the screens, incorporates help menus and also the administration of the test taking, grading, and feedback links. The second functional area (shown in the left column of Figure 2) prompts the author for the actual learning content using for its foundation the instructional design concepts synthesized in Figure 1.

A schematic of the logic flow of the system is shown in Figure 3. 
Figure 3: Flow Diagram of WeBTAS Authoring System

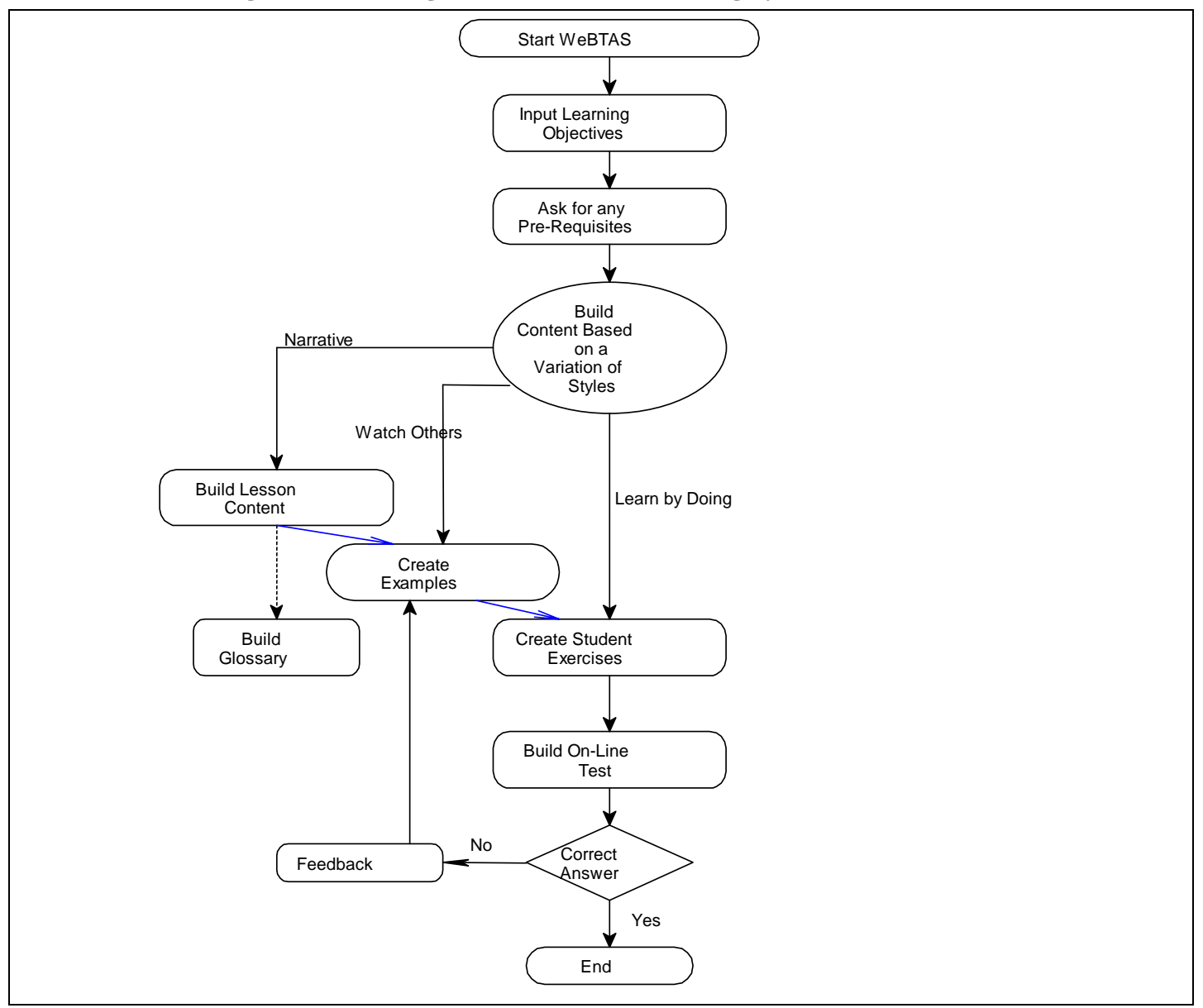

\section{B. Creation of a prototype computer system}

The prototype computer system was written using a combination of Microsoft Visual Basic 6.0, Java Script and CGI (Common Gateway Interface) programming techniques. The authoring system has three major components as shown in Figure 4.

Figure 4: Three Major Programming Components of WeBTAS

\begin{tabular}{|l|l|l|}
\hline $\begin{array}{l}\text { Author creates } \\
\text { learning content in } \\
\text { a variety of } \\
\text { presentation styles }\end{array}$ & $\begin{array}{l}\text { System creates HTML files } \\
\text { and transfers the files to the } \\
\text { web server }\end{array}$ & $\begin{array}{l}\text { Learner interacts } \\
\text { with the materials } \\
\text { previously created. } \\
\text { System monitors } \\
\text { student progress. }\end{array}$ \\
\hline
\end{tabular}




\section{Implementation of the learning principles}

The WeBTAS system has five learning concepts embedded in the authoring process for the developer of a learning module. They are: 1) the definition of learning objectives, 2) the listing of pre-requisite knowledge necessary, 3) three different styles of presenting learning content, 4) permitting the learner to control the pace and direction of the lesson, and 5) provisions for testing and feedback. In addition the system manages the screen design and navigational as well as help menus for the learners and the developers. Each of these principles is discussed in more detail in the following sections.

\section{Clear definition of learning objectives}

Schank [1998] reports that learners need a road map of the lesson plan. Similar to a classroom setting where effective lecturers define their terms early in the course, developers of web-based tutorials should define their terms early. In support of this viewpoint, the first screen for input is the development of the learning objectives for the tutorial.

Figure 5: Building the Learning Objectives for the Tutorial (author view)

Top bar is a menu of the components of the lesson plan the developer will be prompted to create.

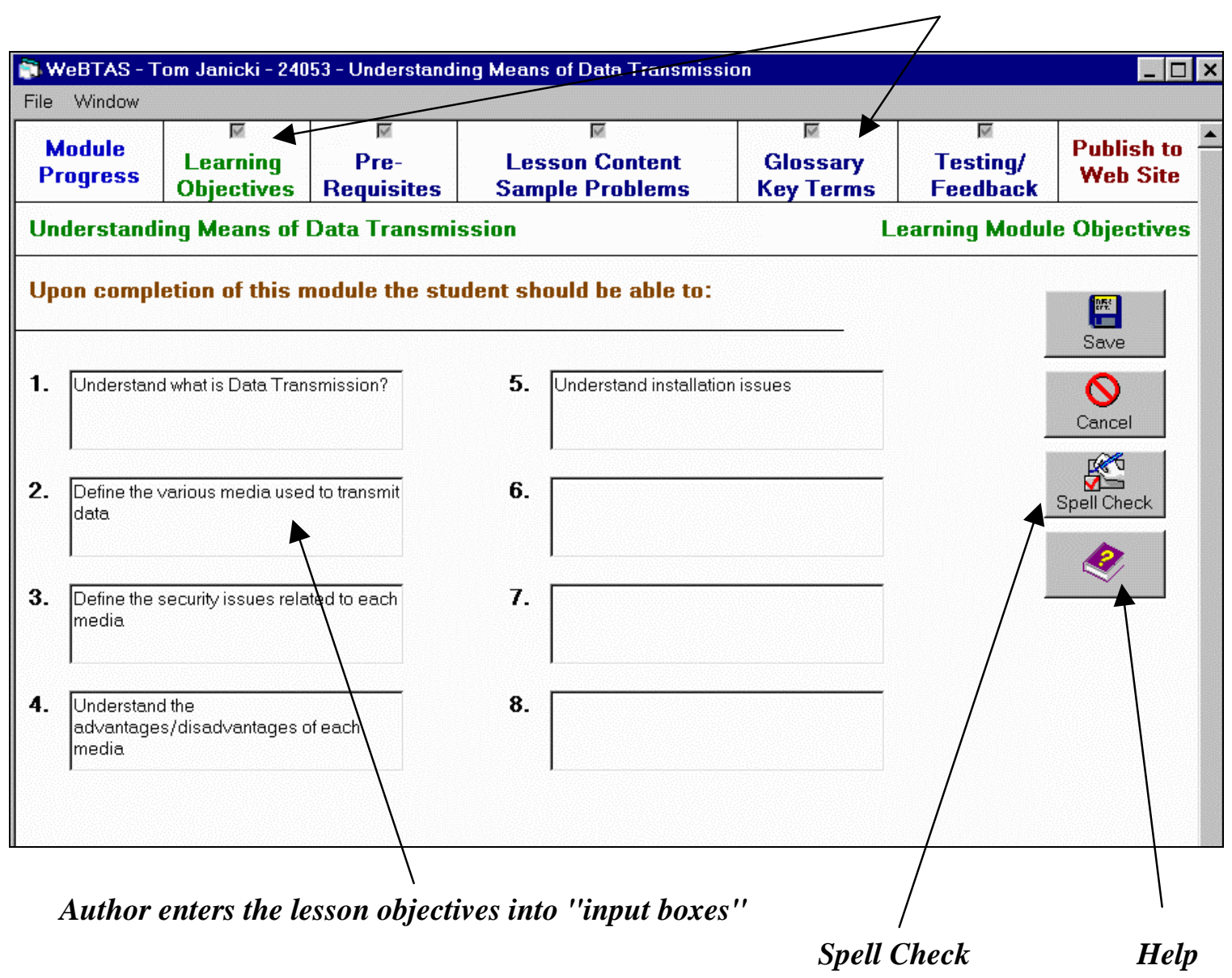

Figure 5 is a screen shot where the instructor (developer) is assisted to build the learning objectives for a particular module. They can build from one to eight learning objectives for a particular tutorial. Spell Checking and Help on building learning objectives is available. In addition, at the top of the screen is a menu bar showing all of the components that the developer 
will be requested to complete. This menu bar is also clickable and provides a backward and forward review of the work completed.

Figure 6: Output of Learning Objectives (learner view)

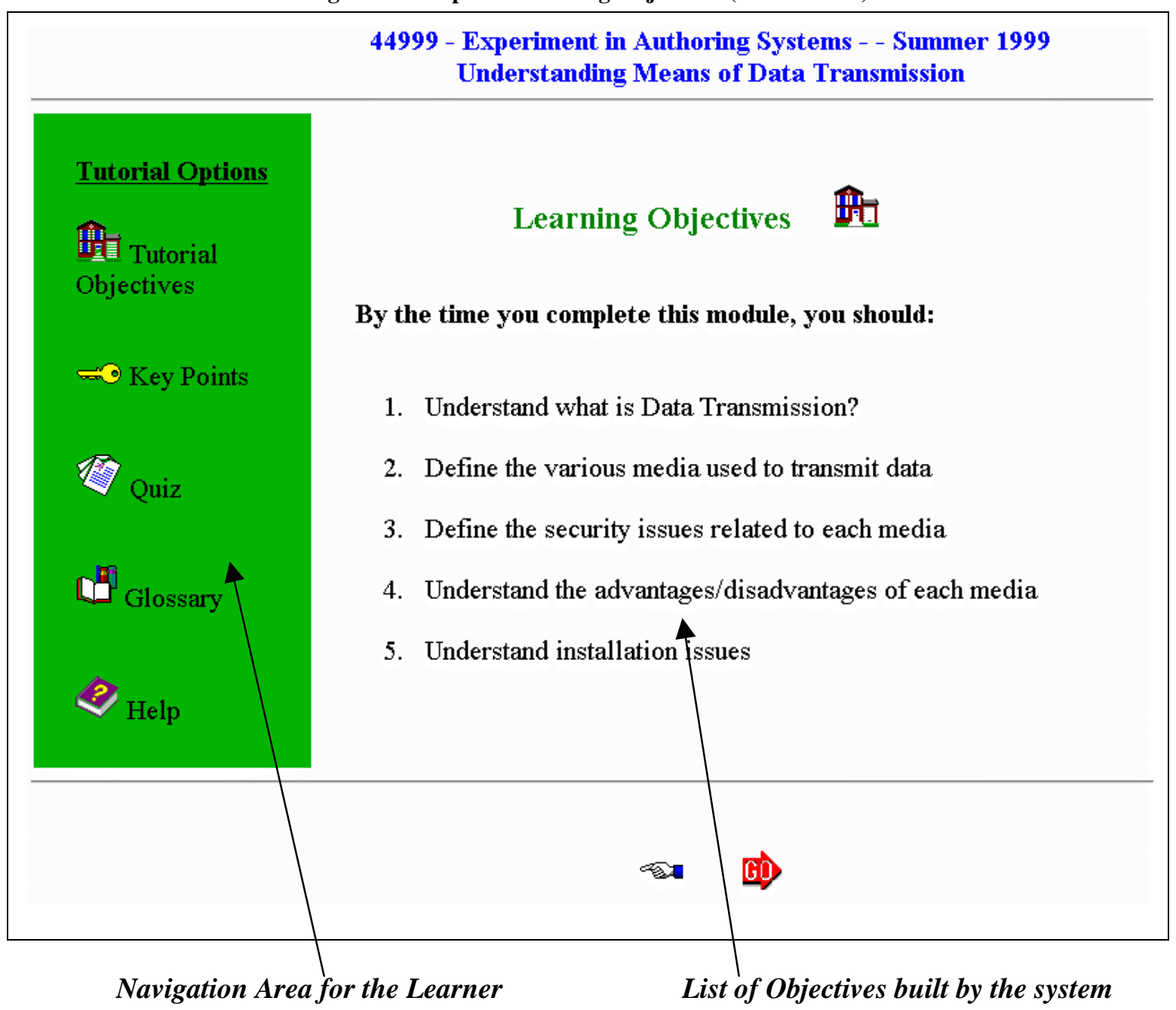

After the author types the learning objectives into boxes, the system manages the creation of all files, and the hyperlinks between files for the developer. It also manages the formatting and translation from text to HTML programming code for the author. The developer never needs to know how to write HTML code, as the system manages that part of the tutorial. Figure 6 is the "output" screen that the learner would be presented on the web based on the "input" of the developer shown in Figure 5.

Figure 7 is the Help screen for this particular learning component. The Help screen provides more than computer and system use help. Notice that it also provides samples of good learning objectives and a list of strong verbs that the developer may want to consider when building the objectives. Most of the help screens in the system provide this level of assistance. 
Figure 7: Help Screen for Learning Objectives

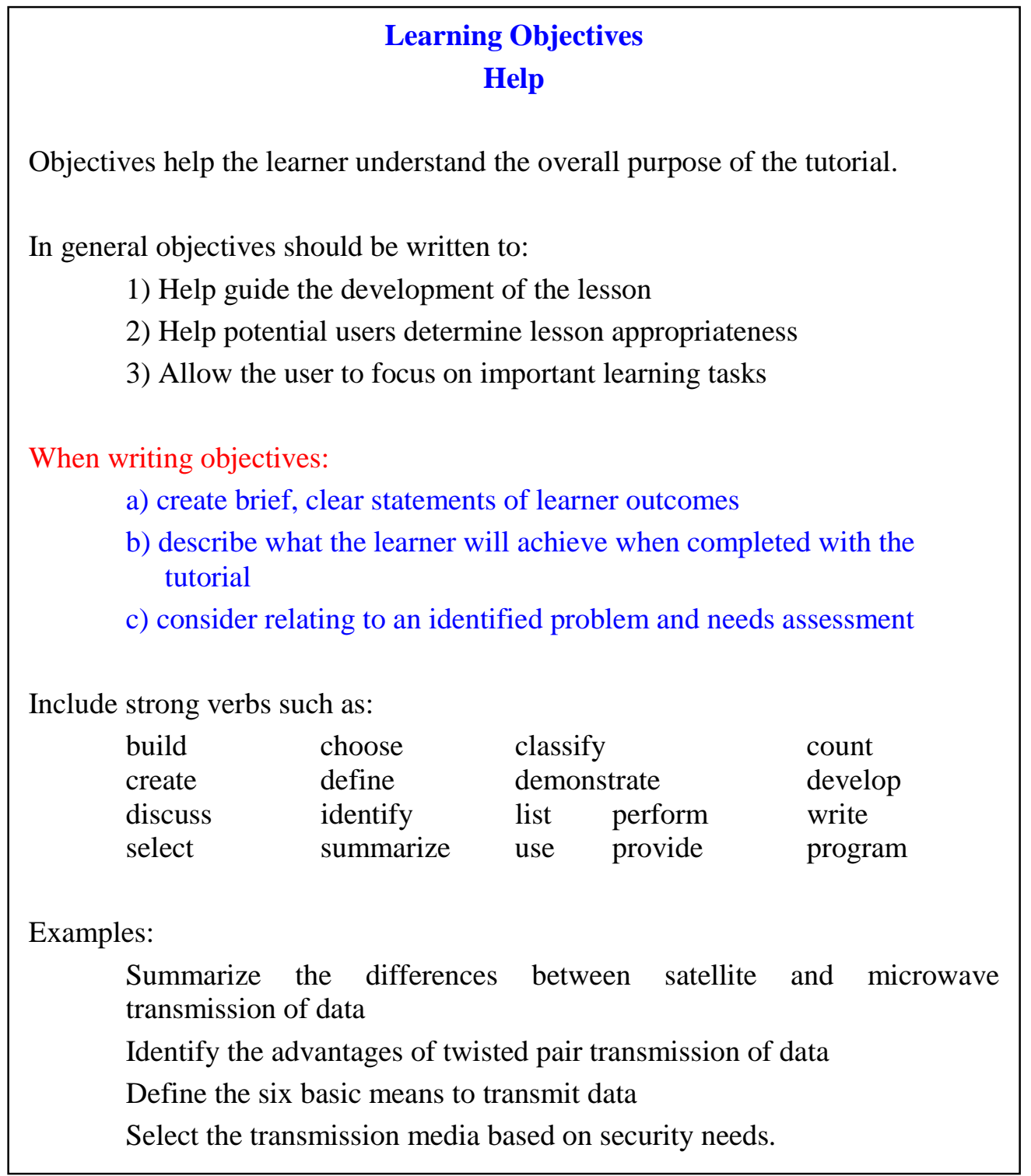

\section{Clear definition of pre-requisite knowledge}

One viewpoint from the cognitive learning theorist is that new knowledge is learned by the merging of previous knowledge with new information [Hannafin \& Peck, 1988]. In a similar view, Brandt [1997] agrees that learners construct knowledge by making sense of experiences in terms of what is already known. The WeBTAS system prompts the developer for a list of the previous knowledge the learner should have acquired prior to beginning this tutorial. It prompts the developer for pre-requisite knowledge in two different manners. First, the system presents the author a list of all tutorials already built for this course (same subject matter). The developer can then indicate if any of the previously built tutorials are pre-requisite knowledge to the current tutorial. If any of the previous tutorials are pre-requisite knowledge to the current tutorial, the system can require (should the developer indicate this option) the learner to complete a previously built tutorial prior to completing the current tutorial. 
The second manner to develop the pre-requisite knowledge is to prompt the author for any additional pre-requisite knowledge and terms and provides a Help screen to reinforce that concept.

\section{Provide a variety of learning styles}

Once the developer has created the learning objectives and the pre-requisite knowledge, the system automatically takes the developer to the construction of the learning content task area. The first task in the lesson content screen is the development of Key Points. A key point is similar to the headings in a handout of the lecture. Once a new key point is entered, the system requests the author to develop the learning content in three different presentation styles. The importance to learning by providing the lesson content in a variety of styles supports the views of Murray [1996], Merrill [1998], Schank [1988], Hannafin \& Peck [1988] and Gagne Wager \& Rojas [1981] as discussed at the beginning of this paper.

Figure 8: Creation of Key Points and Lesson Content in a Variety of Styles (author view)

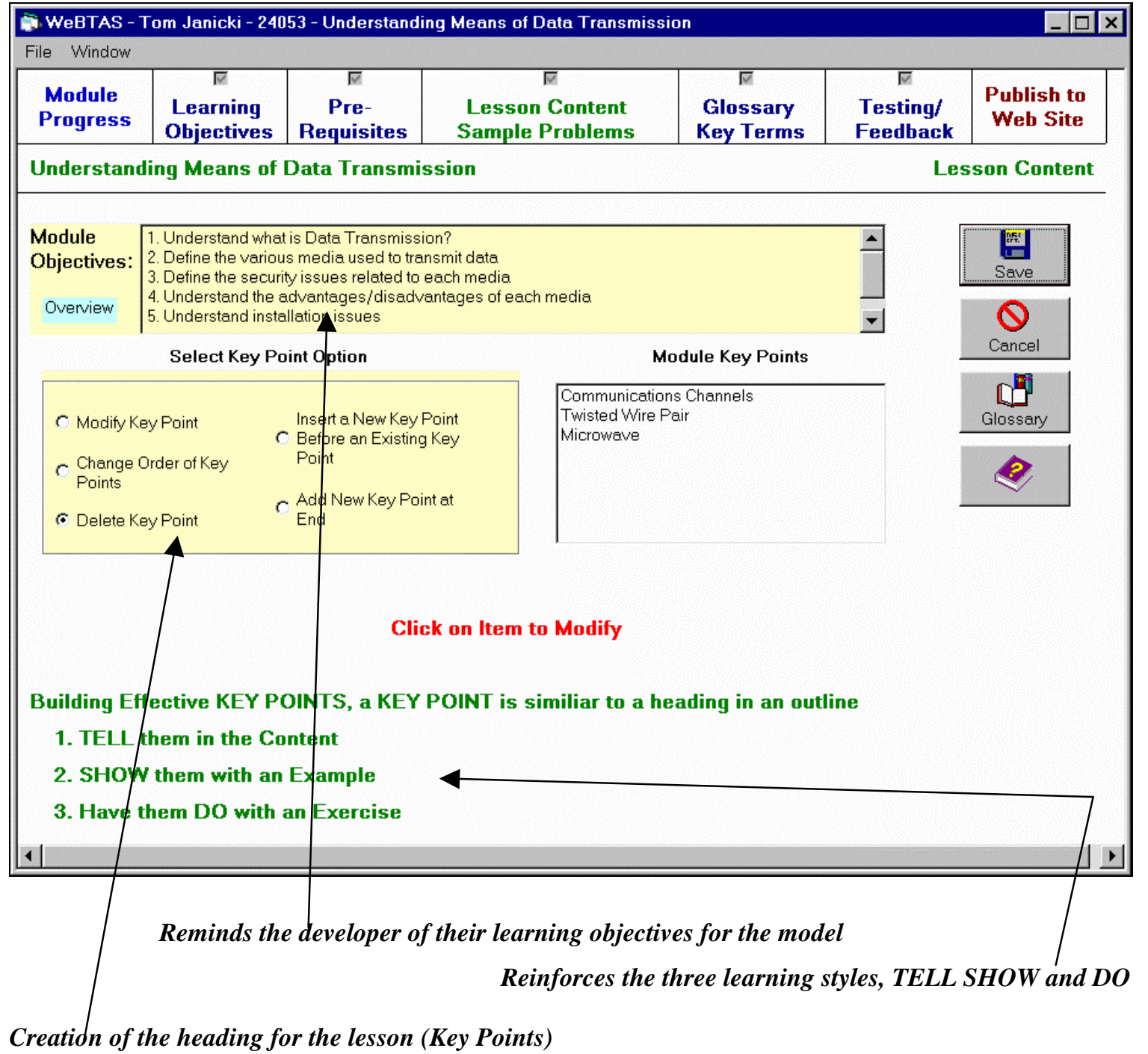

The three varieties of presentation styles supported by the prototype system are narrative (tell), example (show), and exercise (do). Learners have different preferences in the manner they learn best. Some learners like to learn by reading a narrative of new information, as in reading a textbook or article. Collins and Brown [1987] encourage another view of learning style, that 
being the inclusion of examples. They discuss this style of learning as similar to the way crafts are learned from an expert in the field. In the real world, the craft apprentice begins by watching an expert in action and asking questions. Further students may begin the learning process by watching an expert involved in a process or strategy. Then the students will incorporate this experience into their knowledge base and eventually become the craftsperson themselves. In a similar view, Ives [1994] agrees that conceptual knowledge can be closely linked to concrete examples via the multidimensional nature of the World Wide Web.

The third view of learning is the doing of mini-quizzes or exercises. Schank [1998] is a proponent of doing. He views the computer as an excellent device to get learners to do and Schank notes that this doing cannot be accomplished in a traditional classroom. Leinder \& Jarvenpaa [1993], Cole et. al. [1997] and Jonassen et. al [1995] all agree and report that the computer provides the opportunity to provide learners with exercises similar to real world situations. Figure 8 demonstrates the creation or modification of key points.

Once a new Key Point is created, the system takes the author to a screen where the narrative section of the lesson content is developed. The narrative and example screens have the look and feel of a word processor. The toolbars were established to provide familiarity to the author. In addition to typical word processing features, the author may incorporate hyperlinks to other documents, images, sound files and audio files. Figure 9 is a sample screen for building the narrative or lesson content portion of a tutorial.

The building of content narrative is made simple for the author, as this screen is a WYSIWYG (What You See Is What You Get) editor. An additional feature is incorporated to encourage the use of multimedia files or the research capabilities of the web. As the user exits the narrative or example screens, the system checks for the inclusion of hyperlinks and multimedia formats (image, audio, video) in the content. If the system determines that the created content does not contain any hyperlinks or multimedia features, it will prompt the developer to add a hyperlink or image. 
Figure 9: Building Lesson Content (also Examples) - has the look of a word processor (author view)

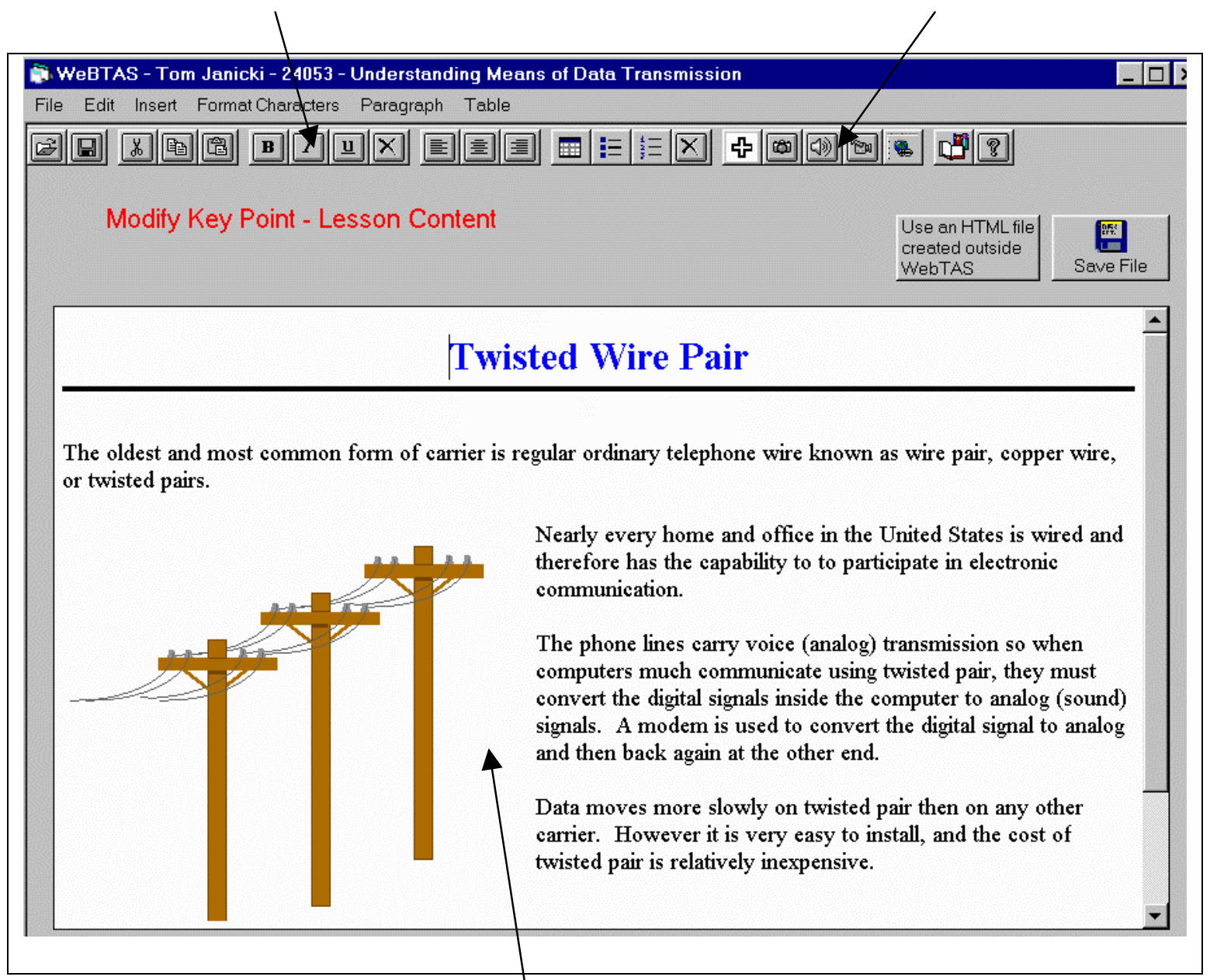

What You See Is What You Get Editor (Creates the HTML code for the developer)

As mentioned earlier, the third variation for presentation of course content is by doing or exercise. The author may create exercises or mini quizzes. Figure 10 shows the mini-quiz editor where the developer may choose from multiple choice, true/false, matching and short answer questions. The author may also include images in any question and also provide enhanced feedback for any answer. 
Figure 10: Creating Mini-Quizzes (author view)

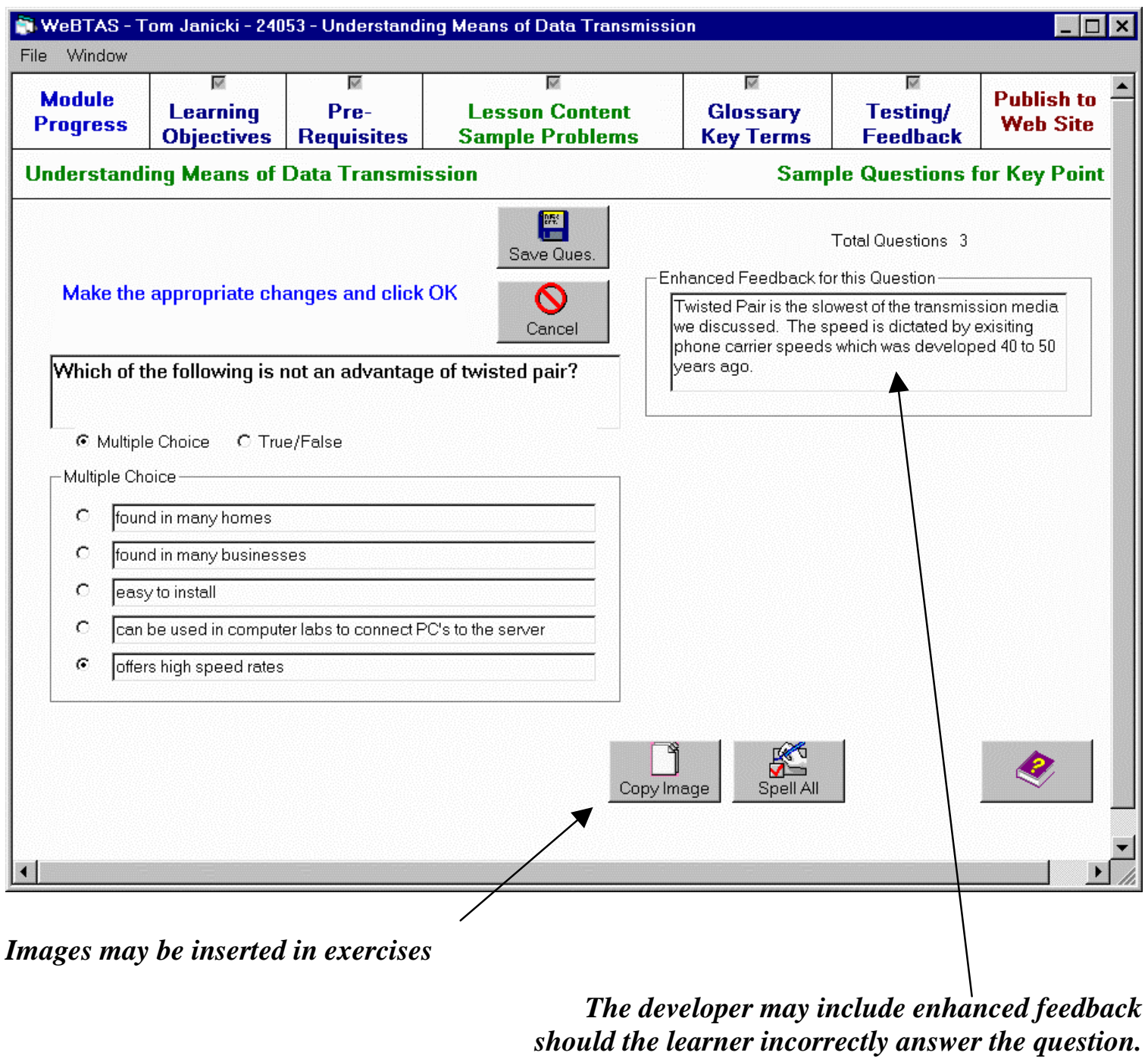

\section{Learner controls the pace and direction of instruction}

Molina [1995], Tennyson [1989], Frasson \& Aimeur [1997] all report the importance of user control of the pace and direction of the learning module. The web is an excellent vehicle to provide this self-paced method of instruction (self-direction by the learner is not available in a typical classroom lecture). However, all authors caution that some control of the flow of the lesson must occur by the developer. WeBTAS does have both of these features incorporated into its design. First the learner must review the learning objectives, pre-requisites, and key points. However, from that point of the lesson on, the learner can control the path through the hyperlinked key points. Some learners may choose only examples, while other may choose the entire complement of narrative (content), examples and exercises. 
Figure 11: Self-Navigational Choices Available to a Learner (learner view)

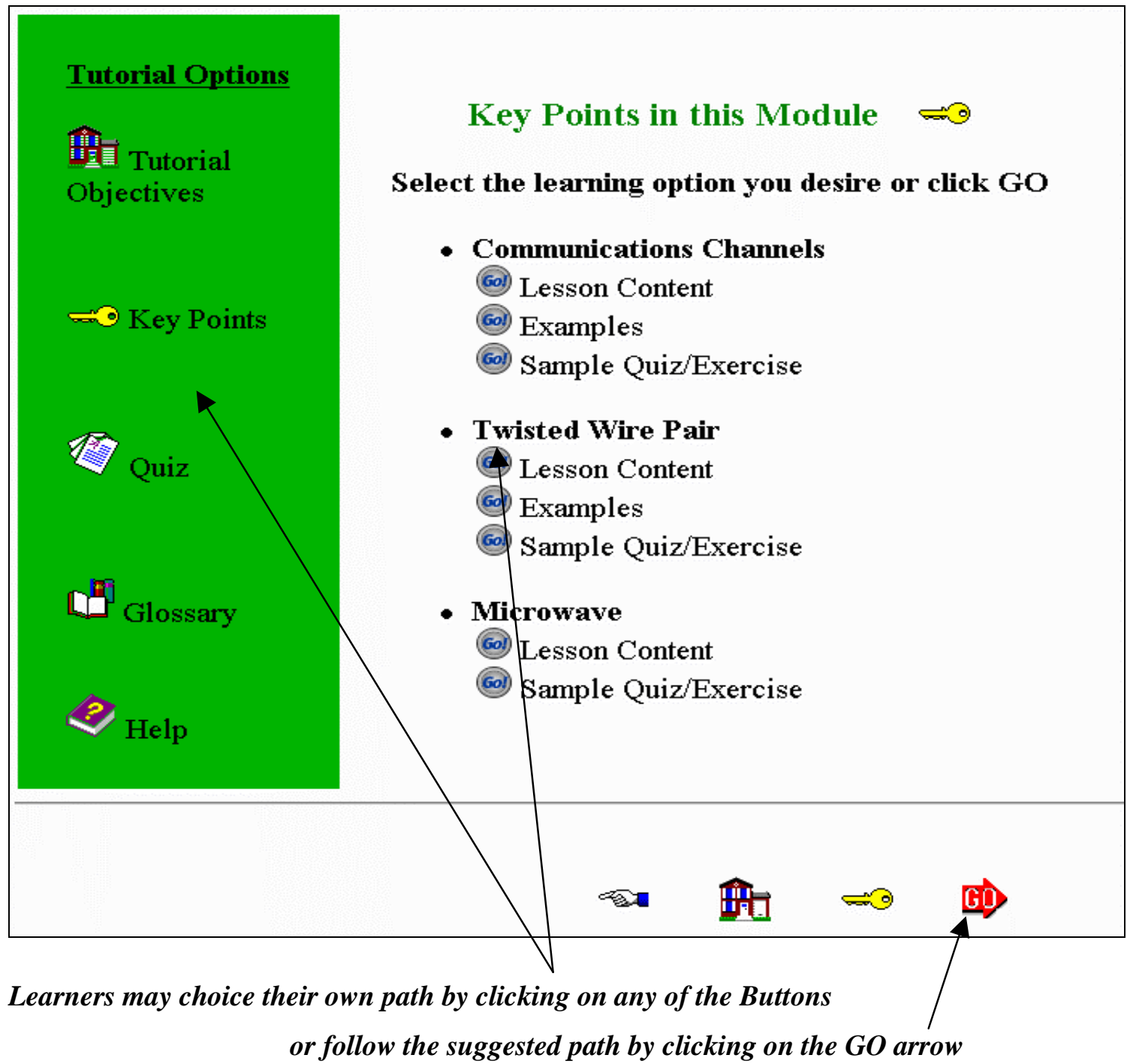

The system monitors the path chosen by the learner, and, following the completion of quizzes, will offer different paths to the user based on what questions in the mini quiz they missed. Molina [1995] reports that a site map should be incorporated into web-design where multiple options are available to a user. As part of the navigation and self-paced direction features, learners are provided a map detailing the entire lesson plan and their current position in that lesson. Figure 11 demonstrates the list of all lesson styles presented to a learner and Figure 12 details a site map with clickable links available to a learner. 
Figure 12: Site Map with Clickable Links to Facilitate Self-Direction (learner view)

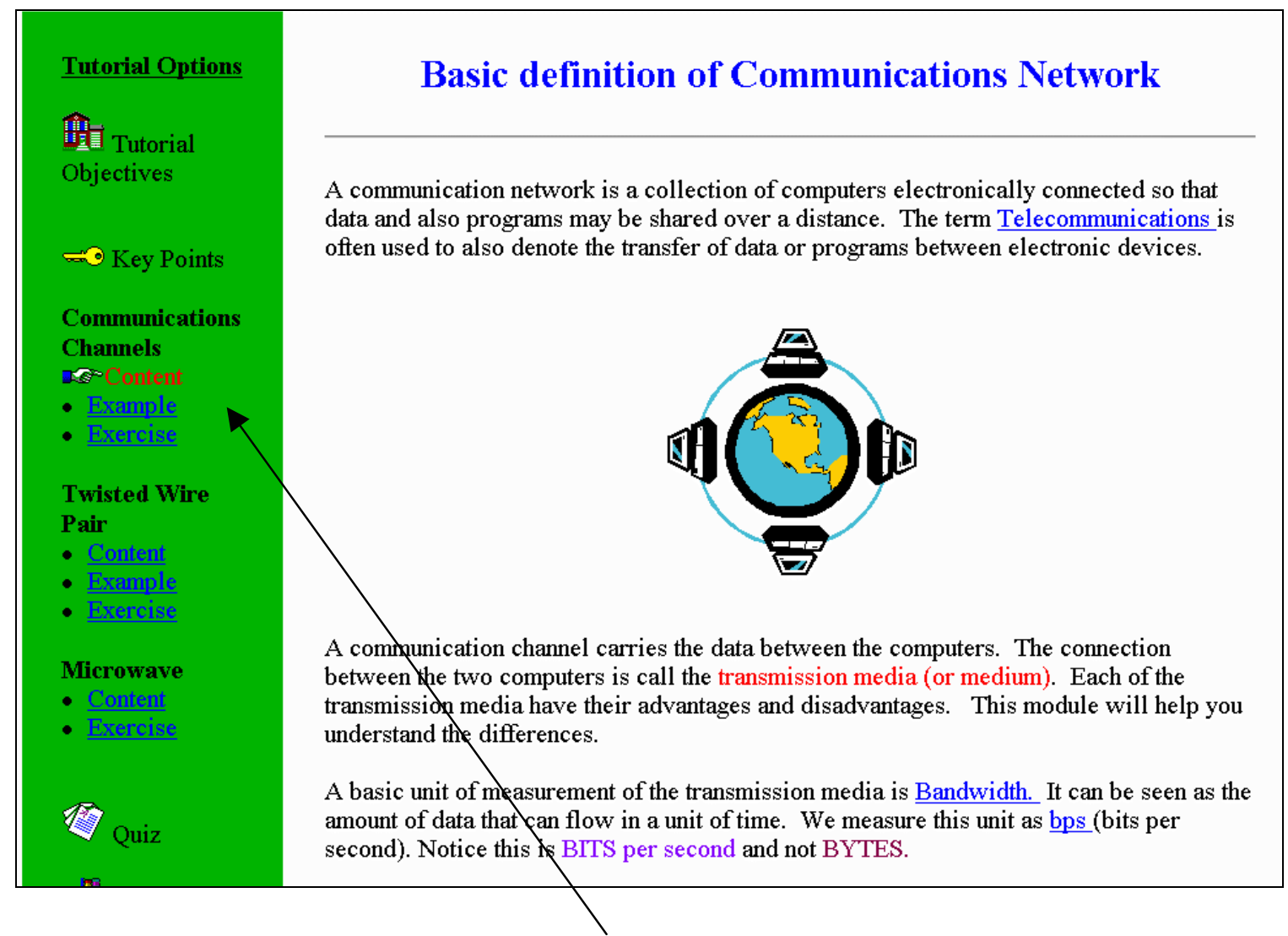

Site Map provided a learner, the hand indicates current position in the tutorial, each of the items in the left bar are hyperlinks to permit self-direction. 


\section{Testing and Feedback}

WeBTAS incorporates various testing formats (true/false, multiple choice, short answer and matching) as discussed earlier. Bugbee [1996] showed that computers can be used for effective testing. The WeBTAS system provides the developer the capability to insert non-graded quizzes, pass/fail quizzes, and graded scored quizzes. It also records and tracks any score on a quiz by an individual learner. Figure 13 shows the screen to creating an end of the tutorial quiz.

Figure 13: Creation of Quizzes at the End of the Tutorial

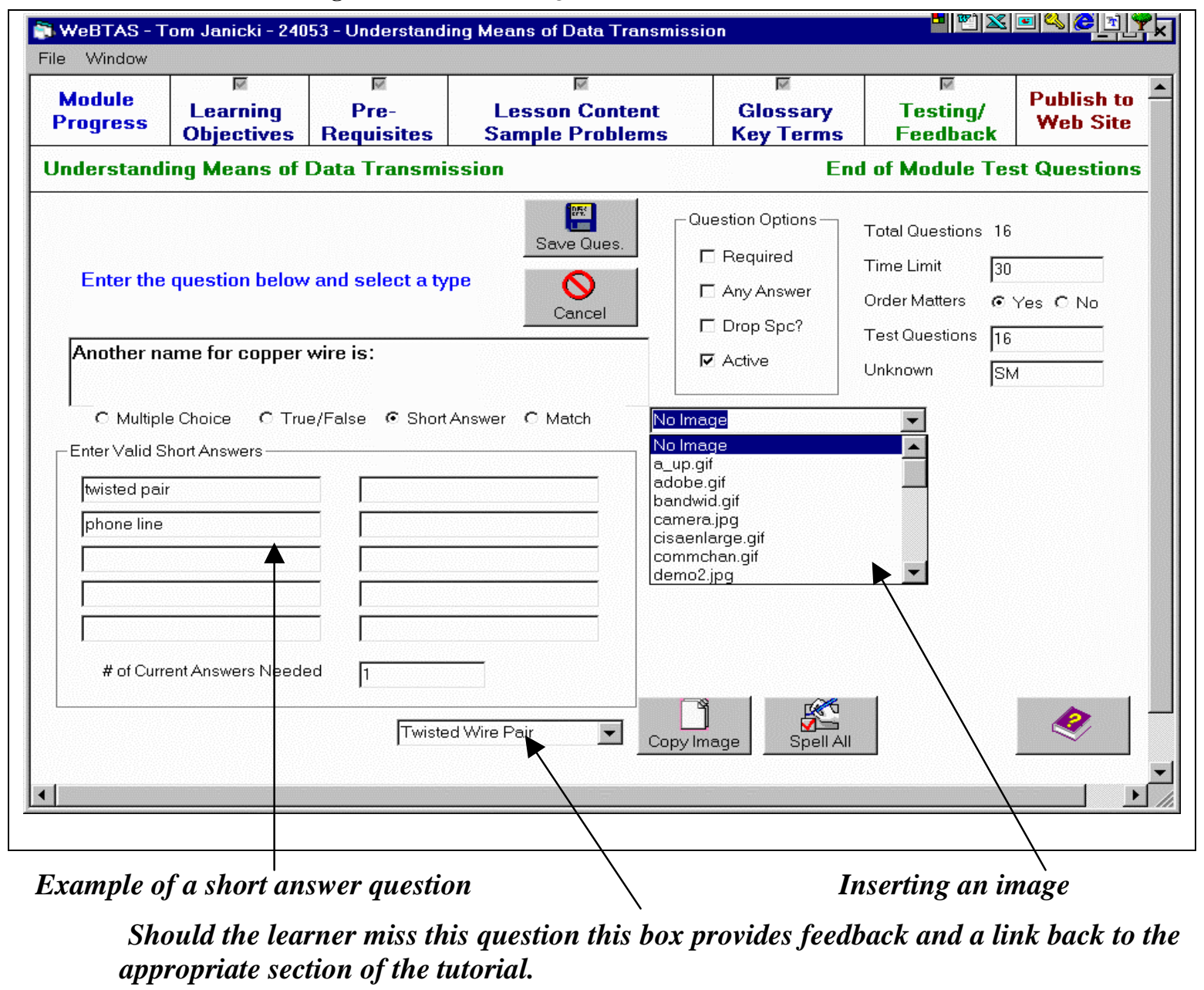

The developer also has several options when adding the feedback capabilities to a tutorial. Cyboran [1995] reports that feedback should be more than "your answer is correct" or "your answer is incorrect" and states that feedback should let learners know why their answer is wrong, use complete sentences and present feedback in the same location on every screen. Based on these recommendations, WeBTAS supports complete sentences and other forms of enhanced feedbacks (links to the source material) that can be added to quiz questions. Figure 10 shows how complete sentences and enhanced feedback can be added to a quiz. 
Figure 14: Insertion of a New Glossary Term

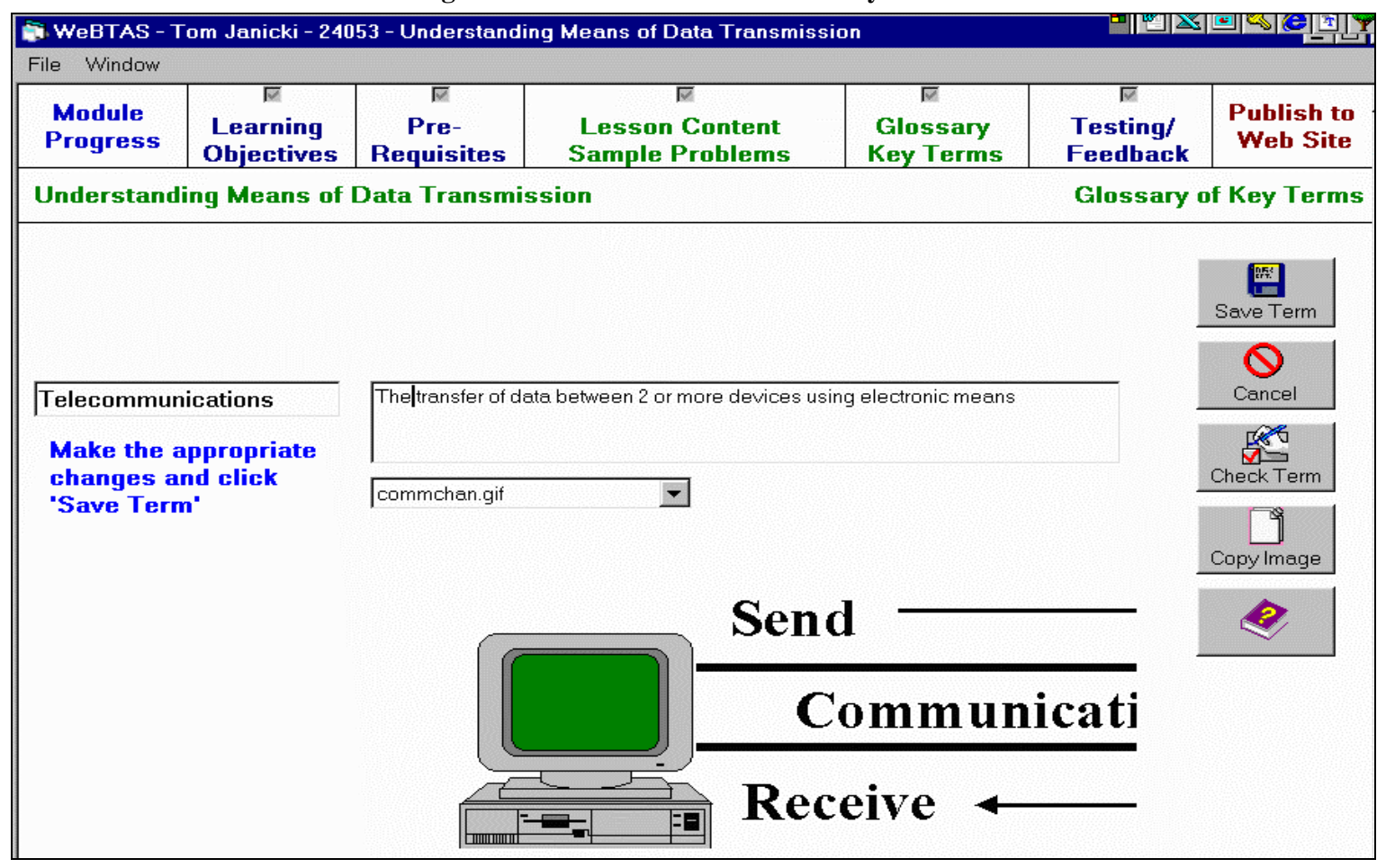

Glossary Feature

To allow the use of special terminology within a lecture document and to further support nonlinear reading patterns, an automated Glossary feature is included in the system. An author may insert a term into a glossary database for any tutorial they create. As they create more tutorials, the expanded Glossary is available to all other modules. A key feature is that any term in the glossary will automatically become a hyperlink in the learning content documents. Should a learner need help on the terminology, all they need to do is click on that term and a definition appears. All of this is managed automatically by the system. Glossary definitions may also include images as shown in Figure 14.

\section{EVALUATION OF THE PROTOTYPE SYSTEM}

Two different surveys were utilized to test the validity of incorporating pedagogy into the prototype system. An expert panel of nineteen educators completed the first survey. They were selected from the instructional technology department of a university. All but one of the panel members had a degree in the educational field. All but three were currently employed in the educational / instructional technology field.

Each of the respondents was provided a brief explanation of the prototype system's goals, a list of the five learning concepts the system claimed to support, hard copies of input screens, help menus, system prompts, and the output produced by the prototype system. They were then asked to rate the adherence of the system to the five learning concepts previously discussed as well as their opinion about the facilitation of effective web-design concepts. The key thrust of the survey was to evaluate the following questions:

Does the system encourage the implementation of the pedagogy it proposes? The proposed pedagogies to be supported are learning objectives, prerequisites, variation of learning styles, testing and feedback and user control.

Does the system employ effective instructional and web design concepts? 
The sign test was used to test each of the hypotheses. The sign test provides a test that measures the number of values above and below an expected mean. In our case a median of 3 on the survey was tested, as on the survey answer of 3 would imply the system had no effect to promote and dissuade the use the particular learning principles. In addition use of the sign test provides a $\mathrm{p}$ value using a binomial distribution. The Wilcoxon Signed Rank Test also provides the estimated median. The first hypothesis tested is stated as follows (all other hypotheses were stated similarly):

$\mathrm{H}_{0}$ : $\mathrm{Mu}$ is 3.0; (the system provides neither positive or negative assistance in establishing learning objectives)

$\mathrm{H}_{1}$ : Mu is not 3.0 (neutral)

Table 2: Expert Panel Survey of the Incorporation of Pedagogy into the Development Process of WeBTAS

\begin{tabular}{|l|c|c|c|c|}
\hline Questions: & Mean & $\begin{array}{c}\text { Std } \\
\text { Dev. }\end{array}$ & $\begin{array}{c}\text { p } \\
\text { value }\end{array}$ & $\begin{array}{c}\text { Wilcoxon } \\
\text { Median }\end{array}$ \\
\hline $\begin{array}{l}\text { Prompts the developer to build learning } \\
\text { objectives }\end{array}$ & 3.89 & 0.81 & .0001 & 4.0 \\
\hline $\begin{array}{l}\text { Prompts the developer for pre-requisite } \\
\text { knowledge }\end{array}$ & 3.95 & 0.85 & .0001 & 4.0 \\
\hline $\begin{array}{l}\text { Prompts the developer to build lesson } \\
\text { content in a variety of styles }\end{array}$ & 3.95 & 1.03 & .0008 & 4.0 \\
\hline $\begin{array}{l}\text { The system provides the learner to self } \\
\text { control the direction and pace of } \\
\text { learning }\end{array}$ & 4.16 & 0.76 & .0000 & 4.0 \\
\hline $\begin{array}{l}\text { The system provides for testing } \\
\text { The system provides for enhanced } \\
\text { feedback }\end{array}$ & 3.84 & 1.17 & .0056 & 4.0 \\
\hline $\begin{array}{l}\text { The system takes advantage of the } \\
\text { web's interactivity }\end{array}$ & 3.78 & 1.06 & .0063 & 4.0 \\
\hline \begin{tabular}{l} 
Scale: \\
\hline 5trongly Agree 4:Agree 3:Neutral 2:Disagree
\end{tabular} & $1:$ Strongly Disagree \\
\hline
\end{tabular}

\section{A. Expert Panel Evaluation}

Overall the findings of the panel of nineteen experts were very positive and did support the assumption that WeBTAS does include the promotion of the five learning principles claimed in the development of the system. All of the p values are very favorable and the Wilcoxon Expected Mean being 4.0 indicates agreement that the system prompted for the learning principles. The confidence interval calculated for each variable is between 3.5 to 4.5 for all variables tested (for testing and feedback the confidence interval is 4.0 to 4.5 ). In summary the null hypotheses that the authoring system's effect was neither positive nor negative on learning principles was rejected. Table 2 summarizes the survey results as it pertains to learning principles and web design. 
The expert panel rated the testing capability (4.26) and self-direction (4.16) with the highest level of agreement. These two learning principles also received the lowest standard deviations indicating a high level of agreement by the expert panels.

All categories were rated in the agreement area, with the lowest ranking (3.78) item being the system capability to take advantage of the web's interactivity. This low score could have been a result of that the expert panel did not get an opportunity to view or work with the system on a computer, as the evaluation was completed on paper only.

Additional comments and suggestions were solicited from the expert panel. Ten of the expert evaluators provided comments to the strengths of the system and five of the evaluators provided comments on the weaknesses. Three commented that the system appeared to be valid and very helpful, but questioned if instructors would want to take the time to develop tutorials in this structured environment.

A sample of comments follows in Table 3:

Table 3: Strengths and Weaknesses of the WeBTAS system (Expert Evaluation)

\begin{tabular}{|c|c|}
\hline Strengths & Weaknesses \\
\hline $\begin{array}{l}\text { - } \text { Appeared simple and easy to use } \\
\text { - } \text { Encourages planning } \\
\text { - } \text { Thorough } \\
\text { - } \text { Designed Well } \\
\text { - } \text { Helpfy to follow } \\
\text { - } \text { Very direct and strong } \\
\text { - } \text { Provides examples } \\
\text { - Clear } \\
\text { - Nicely done, easy to achieve } \\
\text { - Help screens were beneficial } \\
\text { - When can I start using it? }\end{array}$ & $\begin{array}{l}\text { - } \quad \text { Too much work? } \\
\text { - Too long } \\
\text { - Limitation of eight learning objectives } \\
\text { - Key Point screen is cluttered and unclear }\end{array}$ \\
\hline
\end{tabular}

\section{B. Evaluation of the prototype system by pilot group of instructors}

In addition to the survey by experts, a group of ten novice instructors were recruited to "test-out" the system as well as provide web-based tutorials for later experimentation by learners. All of these volunteer instructors had limited teaching experience at the collegiate level, eliminating the effect of an expert instructor in the developmental process. In addition, to reduce a bias of previous knowledge, all of the volunteer developers were not experts in the subject matter of the test-tutorial they had to create (Management), as nine out of the ten of the volunteers were Information Systems majors.

This pilot group of instructors developed web-based tutorials using two different methods for evaluation. The first method was to develop a web-based tutorial using any traditional webauthoring tool, while the second method was to develop a web-based tutorial using the WeBTAS authoring tool. Finally they completed a survey on the use of the system and also the outputs of their efforts were analyzed.

The instructors were divided into two groups (A and B). Assignment of the tutorial developers to each subject group (A or B) was based on the number of courses previously taught. 
Once separated based on their teaching experience they were randomly assigned to a group. This ensured that the same degree of experience was represented in both groups, while still assigning individuals randomly to the groups.

A professor from the Principles of Business Management course chose the two topics for the experiment. The topics chosen were from the employee motivation area, specifically equity motivation theory and simplified expectancy motivation theory. The topics were chosen based on the criteria that none of the volunteer instructors had taught the material previously. Another part of the criteria was these topics would not be discussed in the classroom prior to the laboratory experiment. The procedure to build the tutorial is shown in Table 4.

The result of this phase of the experiment was the creation of ten tutorials by ten different authors for each of the subjects (yielding a total of twenty tutorials). Half of the tutorials (five in equity theory and five in expectancy theory) were built with the WeBTAS authoring system and half using a traditional web-authoring tool. The volunteer instructors were given the option to choose any other HTML authoring tool for the non-WeBTAS tutorial. Eight of the instructors chose PowerPoint, once selected Microsoft Word, and one Notepad. Once in PowerPoint or Word the developers clicked on the convert to HTML wizard embedded in systems.

Table 4: Creation of Web-Based Modules by Volunteer Instructors

\begin{tabular}{|ll|}
\hline \multicolumn{1}{|c|}{ Group A } & \multicolumn{1}{c|}{ Group B } \\
1) Read material on $1^{\text {st }}$ topic & 1) Read material on $1^{\text {st }}$ topic \\
$\begin{array}{ll}\text { 2) Build Equity Tutorial using } \\
\text { traditional authoring tool }\end{array}$ & $\begin{array}{l}\text { 2) Build Expectancy Tutorial using } \\
\text { traditional authoring tool }\end{array}$ \\
$\begin{array}{ll}\text { 3) Read material on } 2^{\text {nd }} \text { topic } & \text { 3) Read material on } 2^{\text {nd }} \text { topic } \\
\text { 4) Build Expectancy Tutorial } & \text { 4) Build Equity Tutorial using } \\
\text { using WeBTAS } & \text { WeBTAS } \\
\text { 5) Complete usage survey } & \text { 5) Complete usage survey }\end{array}$
\end{tabular}

Following the completion of the first tutorial, the volunteers were given a "How to use Guide" on the WeBTAS system and asked to create another tutorial on the alternate topic. It was observed that the instructors were able to complete the WeBTAS and non-WeBTAS tutorials with no additional help or assistance.

\section{Analysis of the two different creation processes}

The experimental results are limited as only ten tutorials were created, but the results show favorable results for the WeBTAS authoring system. Preliminary results indicate that in the same amount of developmental time, the total quantities of lesson content, examples, exercises, and total number of total pages built for the WeBTAS system was equal or higher than the nonWeBTAS. The comparison of the two systems appears in Table 5. 
Table 5 Comparisons of WeBTAS and Non-WeBTAS Tutorials

\begin{tabular}{|c|c|c|c|c|c|c|}
\hline & \multicolumn{2}{|c|}{ Equity Theory } & \multicolumn{2}{c|}{ Expectancy Theory } & \multicolumn{2}{c|}{ Total of Both Tutorials } \\
\hline & WeBTAS & PPT $^{(1)}$ & WeBTAS & PPT $^{(1)}$ & WeBTAS & PPT $^{(1)}$ \\
\hline $\begin{array}{c}\text { Creation } \\
\text { Minutes }\end{array}$ & 97 & 96 & 86 & 83 & 91 & 90 \\
\hline $\begin{array}{c}\text { \# of } \\
\text { Tutorials }\end{array}$ & 5 & 5 & 5 & 5 & 5 & 5 \\
\hline $\begin{array}{c}\text { \# of Slides } \\
\text { (PPT) }\end{array}$ & -- & 7.0 & -- & 7.4 & -- & 7.2 \\
\hline $\begin{array}{c}\text { \# of Learn } \\
\text { Objectives }\end{array}$ & 5.4 & -- & 3.4 & -- & 4.4 & -- \\
\hline $\begin{array}{c}\text { \# of Content } \\
\text { Screens }\end{array}$ & 4.8 & -- & 4.4 & -- & 4.6 & -- \\
\hline $\begin{array}{c}\text { \# of Exam. } \\
\text { Screens }\end{array}$ & 2.0 & -- & 2.0 & -- & 2.0 & - \\
\hline $\begin{array}{c}\text { \# of Quizzes } \\
\text { or Exercises }\end{array}$ & 1.0 & -- & 2.0 & -- & 1.5 & - \\
\hline $\begin{array}{c}\text { Total Pages } \\
\begin{array}{c}\text { Glossary } \\
\text { Terms }\end{array}\end{array}$ & $8.8^{(2)}$ & 7.0 & $9.4^{(2)}$ & 7.4 & $8.3^{(2)}$ & 7.2 \\
\hline
\end{tabular}

${ }^{1}$ PPT $=$ PowerPoint created or an equivalent HTML tool, (Not WeBTAS)

${ }^{2}$ Includes the Learning Objectives as one page

Overall the time to complete the WeBTAS tutorial averaged 91 minutes for the WeBTAS tool versus 90 minutes for the non-WeBTAS tool. We assumed that the total time to create the WeBTAS tutorials would be higher than the PowerPoint lessons due to a learning curve. A question for future research is: would total developmental time decrease with additional exposure to the system. This is important as the WeBTAS system produced additional quantities of learning materials in the same time interval. If the time to develop was to decrease with additional exposure, the adaptation by instructors might be preferred over traditional tools.

The total number of "pages" or screens created was also favorable. The WeBTAS system averaged two additional screens per tutorial in approximately the same amount of time as the PowerPoint built slides.

Another favorable result was the creation of examples and exercises that the WeBTAS system fostered. The researchers expressed the viewpoint of the importance of a variety of learning styles. An analysis of the PowerPoint slides shows them to be primarily content or narrative in nature and not interactive. Two (out of ten) of the PowerPoint presentation did include examples but none included an exercise for the learner.

None of the WeBTAS built systems included any hyperlinks to any other research material. This might be explained as the volunteer instructors were not the course instructor for the subject matter and were unaware of any additional course material available from the book publisher or other resources on the web. 
Finally, the instructors used the glossary option an average 2.6 times per lesson. While this is not significant to this study, as the real benefit to the learner of the glossary occurs when there are number of tutorials created in the same subject area it still shows the ease of use and the future potential of this feature.

\section{Instructor Survey Results}

Following the completion of building both tutorials, the instructors completed a survey to rate the new system and seek input for future enhancements. The survey results were very favorable with all categories in the "agree" and most between agree and strongly agree. Table 6 details this survey, with the signs test used to measure the null hypotheses that the system effect on the learning principles was neutral. Since the data sample is small these results need to be tested with a larger sample.

Table 6: Instructor Survey Summary

\begin{tabular}{|c|c|c|c|}
\hline Questions: & Mean & $\begin{array}{l}\text { Standard } \\
\text { Deviation }\end{array}$ & $\begin{array}{l}\mathrm{p} \text { value using } \\
\text { signs test }\end{array}$ \\
\hline WeBTAS was easy to use & 4.4 & 0.52 & .0020 \\
\hline $\begin{array}{l}\text { Prompted me to include learning objectives that } \\
\text { I would not have considered }\end{array}$ & 4.5 & 0.97 & .0215 \\
\hline $\begin{array}{l}\text { Prompted me to include pre-requisites that I } \\
\text { would not have considered }\end{array}$ & 3.8 & 0.92 & .0703 \\
\hline $\begin{array}{l}\text { Prompted me to divide the material into small } \\
\text { segments called Key Points that I would not } \\
\text { have considered }\end{array}$ & 3.7 & 1.34 & .5078 \\
\hline $\begin{array}{l}\text { Prompted me to include student exercises } \\
\text { (quizzes) that I would not have considered }\end{array}$ & 4.4 & 0.70 & .0039 \\
\hline $\begin{array}{l}\text { Prompted me to include multi-media that I } \\
\text { would not have considered }\end{array}$ & 4.1 & 1.10 & .0703 \\
\hline $\begin{array}{l}\text { Prompted me to include a Glossary that I would } \\
\text { not have considered }\end{array}$ & 4.4 & 0.70 & .0039 \\
\hline $\begin{array}{l}\text { Taught me new information about building } \\
\text { tutorials built on pedagogy }\end{array}$ & 4.7 & 0.48 & .0020 \\
\hline $\begin{array}{l}\text { I believe I will maintain this knowledge of } \\
\text { pedagogy and use it in the future }\end{array}$ & 4.6 & 0.52 & - \\
\hline $\begin{array}{l}\text { I believe I will use this pedagogy in my } \\
\text { classroom teaching }\end{array}$ & 4.8 & 0.42 & - \\
\hline
\end{tabular}

Scale: $\quad$ 5:Strongly Agree 4:Agree 3:Neutral 2:Disagree 1:Strongly Disagree

As a side benefit, many of the instructors reported that the system had taught them something about learning theory and indicated they would use this knowledge in their classrooms. This could be related to the fact that these were novice instructors with limited teaching experience. 
The instructors were also asked to rank what features were the most beneficial and what features of the system were least beneficial. The most beneficial features were the HTML assistance (that they did not have to create HTML code, the system did it for them) in building lesson content, the quiz editor and variety of presentation styles. This is encouraging as the system was designed to not require the author to know any HMTL programming code as it transforms a WYSIWYG input screen to HTML. The capability to add interactive (non-graded and graded) exercises and quizzes was also well received.

The least beneficial features were Spell Checking and prompting for pre-requisites. It should be noted that many of the authors did not spell check their work, and this is one feature that will be made automatic in future releases.

The final portion of the survey asked for suggestions for improvement on areas that were unclear. Their suggestions were:

- Would like to see a map of the entire lesson plan like "preview" in PowerPoint

- Increase the library of images available

- Provide clipart images

- Provide special character capability

Other comments included:

- Much more organized approach

- Forces consideration of learning tools

- Learning approach was easy

- Trying objectives to Key Points was beneficial

- Integrated approach

- After one key point was able to use without help

- Potential linking of additional tutorials and glossary of terms

In summary the survey results were very favorable and indicated a high degree of acceptance by the volunteer instructors. Future research questions would include measuring the developmental time of future modules to determine if there was a learning curve effect, and attempt to measure the benefit of the glossary of terms and pre-requisites.

\section{DISCUSSION}

This paper summarizes and details the incorporation of learning principles into a new Web-Based Authoring system. It reviews the process of verifying that five learning principles had been incorporated into the authoring process. These principles were: a clear definition of learning objectives, listing of pre-requisite knowledge, providing a variety of presentation styles, enhanced feedback and testing, and permitting the learner to control the pace and direction of the learning module.

Two different approaches were used to test the validity that the system actually incorporated pedagogy and effective web-based design concepts as part of the developmental process. First a group of educational experts were surveyed to seek their opinion if the authoring system did incorporate the five learning principles into its design. Their survey results validated that the system would prompt developers to build a tutorial based on pedagogy. In addition a high agreement was noted in the self-direction and pace of the lesson offered to the learner. Additional comments encouraged the expansion of more multi-media capabilities and a better definition of the terms used in the system.

In a second means to validate the system, ten volunteer instructors were recruited to develop tutorials using two different authoring systems. Volunteers built one tutorial using a tool of their 
choosing and then one tutorial using WeBTAS. Eight of out ten volunteers chose PowerPoint as the vehicle to build their tutorials.

The analysis of the results show that the total development time spent on both systems was identical (within one minute), and that the WeBTAS system created an average of two more screens of tutorial content in the same amount of creation time. In addition the WeBTAS system provided for a variety of presentation styles (tell, show, and do while the PowerPoint slides were primarily of the "tell" or "narrative" variety. A total of two PowerPoint slides did have examples incorporated into their narrative, but none had any exercises for the learner.

The instructors ranked the new system easy to use and did agree that the system prompted them for lesson content in an organized and coherent manner. The capability to create online quizzes, an online glossary and key points ranked high in a listing of features.

Although the system does exhibit positive results after a pilot test, a question for future research is the implementation of the system with learners. This research would provide evidence that the learning concepts incorporated into the system do impact learning in a positive manner. On the positive side the survey results from the two different panels and the materials produced by the system provides indication that the system is a positive benefit to instructors and developers of web-based training materials.

\section{REFERENCES}

1. Alavi, M. (1994). Computer mediated collaborative learning: an empirical evaluation. MIS Quarterly, 18 (2), 159-174.

2. Anderson, J. and Reiser, B.(1985) The LISP tutor. Byte Magazine, 10 (4), 159-175.

3. Atkinson, J. (1996). Director of Distance Learning Applications, Interview 2/96.

4. Barrett-Murie, D. (1995). Distance Learning spurs growth in VSAT Market. Satellite Communication, 19 (9), 87-90.

5. Bork, A. (1986). Advantages of computer based learning. Journal of Structured Learning, 9 (1), 63-76.

6. Brown, J. (1990). Toward a New Epistlemology for Learning. In Frasson and Gauthier (eds). Intelligent Tutoring Systems (pp. 266-281). Norwood NJ: Ablex Publishing Corporation.

7. Bugbee, A. (1996). Equivalence of paper and pencil and computer based testing. Journal of Research on Computing in Education, 28 (3), 282-299.

8. Cassidy, P. (1995). Virtual Campus: New technology reaches student far beyond the classroom. LAN Times, 12 (26), 86.

9. Cole K.; Fischer, O.; and Saltzman, P. (1997) Just-In-Time Knowledge Delivery. Communications of the ACM, 40 (7), 49-53.

10. Cyboran, V. (1995) Designing Feedback for Computer-based Training. Performance \& Instruction, 34 (5), 18-23.

11. Dear, B. (1987). AI and the Authoring Process. IEEE Expert, 2 (4), 17-23.

12. Dick, W. and Carey, L. (1996). The Systematic Design of Instruction. New York: Harper Collings

13. Frasson C. and Aimeur E. (1996). A comparison of three learning strategies in intelligent tutoring systems. Journal of Educational Computer Research, 14 (1), 363-371.

14. Freedman, R. (1987). Expert systems that teach. IEEE Expert, 2 (4), 16-32.

15. Gagne, R.; Briggs, L. and Wager, W. (1988). Principles of Instruction Design Third Edition. New York: Holt, Reinhard, \& Winston.

16. Gagne, R.; Wager, W. and Rojas, A. (1981). Planning and Authoring Computer-Based Instruction Lessons. Educational Technology, 21 (9), 17-26.

17. Goldberg M.; Slari, S. and Swoboda, P. (1996). WW Course Tool: an environment for building WWW based Courses, Fifth International WWW Conference, Paris. 
18. Gubernick L. and Ebeling A. (1997). I got my degree through E-mail. Forbes Magazine, 6/16/97.

19. Hamalainen, M.; Whintson, A. and Vishik, S. (1996). Electronic markets for learning: education brokerages on the Internet. Communications of the ACM, 39 (6), 51-58.

20. Hannafin, M. (1992). Emerging technologies, ISD, and learning environments: Critical perspectives. Educational Technology, Research and Development, 40 (1), 463-496.

21. Hannafin, M. and Peck, K. (1988). The Design Development and Evaluation of Instructional Software. New York: MacMillian Publishing.

22. Ives, B. (1994). Transforming the Learning Industry, MIS Quarterly, 18 (1), v-vii.

23. Ives. B. and Jarvenpaa, S. (1996). Will the Internet revolutionize business education and research? Sloan Management Review, 37 (3), 33-40.

24. Jonassen, D.; Davidson, M.; Collins, M.; Campbell J.and Haag, B. (1995). Constructivism and Computer Mediated Communication in Distance Education. American Journal of Distance Education, 9 (2), 7-25.

25. Lebow D.; Wager, W.; Marks, P. and Gilbert N. (1996). Construe: software for collaborative learning over the World Wide Web. Proceedings of the AECT collaboration in distance education conference, (pp. 1-15). Tallahassee FL: AECT.

26. Leidner, D. and Jarvenpaa, S. (1993). The Information Age Confronts Education: Case Studies on Electronic Classrooms. Information Systems Research, 4 (1), 24-51.

27. Liegle, J. and Madey, G. (1997). Investigations into Technologies for Distributed Learning. Proceedings of the Midwest DSI Conference, Indianapolis: DSI.

28. Martin, T. (1995). The development of interactive WWW courseware for students of engineering and technology at deakin university. Proceedings of the Australian World Wide Web Conference. Lismore Australia: AUSWEB.

29. McGee, M. (1998). Save on Training, Information Week, n708, 141-146.

30. Merrill, M.D. (1997). On Instructional Strategies. Instructional Technology Magazine, 2 (1).

31. Merrill, M. D. (1988). The Role of Tutorial and Experiential Models in Intelligent Tutoring Systems. Educational Technology, 28 (7), 7-13.

32. Molina, C. (1995). Transitioning to CBT. Performance \& Instruction, 35 (9), 26-33.

33. Murray, T. (1998). Authoring Knowledge Based Tutors: Tools for Content, Instructional Strategy, Student Model, and Interface Design. Journal of the Learning Sciences, 7(1) 5-64.

34. Murray, T. (1996). From Story Boards to Knowledge Bases, the First Step in Making CAI 'Intelligent'. In Carlson \& Makedon (Eds.) Educational Multimedia and Hypermedia, Proceedings, (pp. 509-514). Charlottesville VA: AACE.

35. Niederman, F.; Brancheau, J. and Wetherbe, J. (1991). Information systems management issues for the 1990's. MIS Quarterly, 15 (4), 475-500.

36. Patterson, J. and Smith, W. (1994). North Carolina Information Highway, IEEE Network, 8 (6), 12-17.

37. Robin, B. and McNeil, S. (1997). Creating a course-based web site in a university environment. Computer \& Geosciences, 23 (5), 563-572.

38. Schank, R. (1993). Learning Via Multimedia Computers. Communications of the ACM, 36 (5), 54-56.

39. Schank, R. (1998). Horses for courses. Communications of the ACM, 41 (7), 23-25.

40. Setteng, G. (1995). Wireless Infrared network in the Duke paperless classroom. T.H.E. Journal, 23 (3), 87-93.

41. Solomon, C. (1986). Computers environments for children. Cambridge, MA: The MIT Press.

42. Tennyson R. (1989). Cognitive Science and Instructional Technology: Improvements in Higher Order Thinking Strategies. Proceedings of the Association for Educational Communication \& Technology, Dallas TX: AECT. 
43. Ward, E. and Lee, J. (1995). An instructors guide to distance learning. Training \& Development, 49 (11), 40-44.

\section{Internet (HREF) Resources}

44. Allen Communications - http://www.allencom.com

45. AT\&T Joins leading universities in distance learning alliance http://www.att.com/press/1094/941012.gba.html

46. WebCT Editor - http://homebrew1.cs.ubc.ca/webct/get/pricing.html

47. Westcott Corp. - http://www.westcott.com/Default.htm

48. Ziff Davis University - http:// www.zdu.com

\section{ABOUT THE AUTHORS}

Thomas N. Janicki is assistant professor of management information systems, at the University of North Carolina, Wilmington. B.S., Carnegie Mellon University; M.B.A., University of Pittsburgh; Ph.D., Kent State University.

Jens O. Liegle is assistant professor in the Department of Computer Information Systems, in the J. Mack Robinson College of Business, at Georgia State University in Atlanta, Georgia. Bachelor of Business Administration, May 1992, Pforzheim Business School, Master of Business Administration (MBA), University of Akron Doctor of Philosophy in Management Systems, Kent State University. 